\title{
Geographic Geolocation Search in Real Estate Marketplaces
}

\author{
Laura Martínez, Mag. ${ }^{1}$, Juan Contreras, PhD. ${ }^{2}$, and Libis Valdez, Mag. ${ }^{1}$ \\ ${ }^{1}$ Fundación Tecnológica Antonio de Arévalo, Colombia, laura.mgarcia@tecnar.edu.co, libis.valdez@tecnar.edu.co \\ ${ }^{2}$ Corporación Universitaria Rafael Núñez, Colombia. epcontrerasj@ieee.org
}

\begin{abstract}
The article describes how the geographic geolocation can offer a great opportunity for the real estate sector to create maps, where customers can consult the location of the property, view the environment of the residential and commercial locations around the property without having to travel physically to the site. This functionality can significantly help clients make good purchasing decisions and sales by displaying important information on the map.
\end{abstract}

Keywords-Geolocation, google maps, street view, real state system.

Digital Object Identifier (DOI): http://dx.doi.org/10.18687/LACCEI2015.1.1.280

ISBN: 13 978-0-9822896-8-6

ISSN: 2414-6668

$1^{\text {th }}$ LACCEI Annual International Conference: “Engineering Education Facing the Grand Challenges, What Are We Doing?” July 29-31, 2015, Santo Domingo, Dominican Republic ISBN: 13 978-0-9822896-8-6

ISSN: $2414-6668$

DOI: http://dx.doi.org/10.18687/LACCEI2015.1.1.280 


\title{
Geographic Geolocation Search in Real Estate Marketplaces
}

\author{
Laura Martínez, Magister ${ }^{1}$, Juan Contreras, $\mathrm{PhD}^{2}$, and Libis Valdez, Magister ${ }^{1}$ \\ ${ }^{1}$ Fundación Tecnológica Antonio de Arévalo, Colombia, laura.mgarcia@tecnar.edu.co, libis.valdez@tecnar.edu.co \\ ${ }^{2}$ Corporación Universitaria Rafael Núñez, Colombia. epcontrerasj@ieee.org
}

\begin{abstract}
The article describes how the geographic geolocation can offer a great opportunity for the real estate sector to create maps, where customers can consult the location of the property, view the environment of the residential and commercial locations around the property without having to travel physically to the site. This functionality can significantly help clients make good purchasing decisions and sales by displaying important information on the map. system.

Keywords: Geolocation, google maps, street view, real state
\end{abstract}

\section{INTRODUCTION}

In recent years, real estate has shown a recent acceleration in the increase in construction. However, this growth requires real estate companies to find potential customers in different areas.

Today, all property should be positioned on the Internet, if the goal is to evolve as a company and win international markets [1]. A marketplace offers an interesting solution for real estate where in just one place can integrate various companies, in order to perform operations of property management, maintaining close customer relationships and provide search services [2].

The marketplaces bring the concept of Web 2.0 which covers a range of interactive applications that provide network services to the user. One such application is the mashup, which have the ability to collect information from various websites like google maps, flickr, amazon, youtube and other internet sources. According to Song Lin, Gao Zhiguo, $\mathrm{Xu} \mathrm{Ke}$ the Mashup combine data from more than one source into a single app [3]. A website through a Google Maps service, can get information of streets and places, including satellite imagery [4], which adds new features completely innovative in the operation of the portal.

In this paper, we describe a real estate portal in the category of Marketplaces and Mashup, which links the API Google Maps and Street View to its search system to provide the user information on the geographical location of the property.
An API, Application Programming Interface, is the set of functions and procedures that provides a library to use by other software as an abstraction layer. Google Maps API is a service developed in JavaScript that provides satellite images of the entire planet, combined with maps of cities that when implemented in an application has the ability to scroll through a precise point on the map with the possibility of searching for sites, places, businesses and cities.

Through maps Google Maps, users can embed in the pages custom maps on their own websites. The API provides a set of utilities for manipulating and add content to the map through services that enable developers to create robust location-based applications on websites. According to the official website of Google, you can create location-based applications, create maps for mobile applications, and visualize geospatial data through 3D images with Google Earth and Maps Google Fusion Tables heat.

Google Street View is an application which allows a virtual tours for public spaces and attractions through panoramic street-level (360 degrees of horizontal movement and 290 degrees of vertical movement), allowing to see indications of the tracks, turns, names and street numbers to get from one place to another in a guided manner through images.

\section{ARQUITECTURE OVERVIEW}

Our proposed innovation considers the implementation of a vertical marketplace, development in Java Enterprise Edition technology, which aims to create equal conditions in the real estate sector offering facilities in managing property, keeping market relationships with domestic and overseas customers through a single platform. A marketplace is an excellent idea if the goal is generates more traffic visits from potential customers and management costs of the websites of real estate companies that comprise it are minimized.

INMO is a web application with $\mathrm{N}$ Layers, where clients connect to the application through a HTTP or HTTPS connection. For communication between objects using the Spring Framework version 3.0 for dependency injection.

\section{GOOGLE MAPS API}

$1^{\text {th }}$ LACCEI Annual International Conference: “Engineering Education Facing the Grand Challenges, What Are We Doing?” 
The communication of the application is developed by means of messages between objects, and as its N-tier architecture. The communication to the lowest level working with RMI (Java Remote Method Invocation), which is standard execution environment Java and provides a simple mechanism for communication in distributed applications server.

INMO presents a model of separate layers, which makes it extensible and easy to maintain. Each layer has a specific function and through APIs exist communication between presentation, business logic and data access. This style is organized hierarchically, where each layer provides services to the upper layer and lower layer to end users.

The system has the architecture shown in Figure 1, which shows the various components that comprise it through a layered architecture programming.

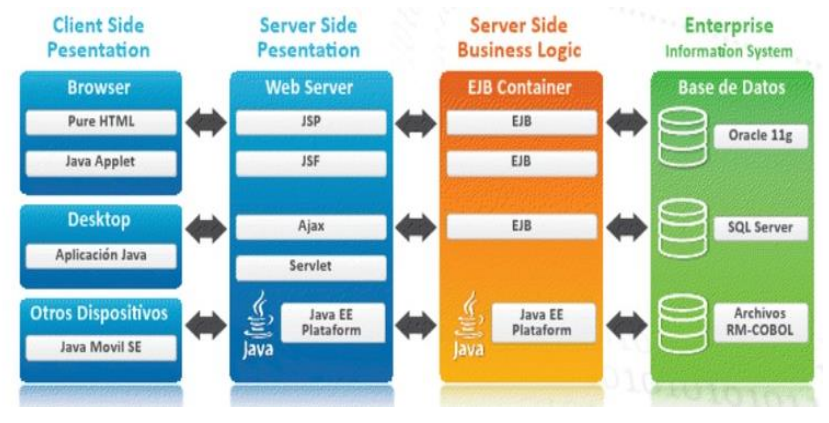

Figure 1. System Architecture of the Real Estate Marketplace

The Presentation layer was developed through JavaScript and JSP (Java Server Pages) which displays information to the user via web browser and mobile client. This app use the framework Prime Faces which has support AJAX, allowing control which components of the current. Also, use JavaServer Faces (JSF) in order to simplify the development of user interfaces in the application and Managed Beans for data management.

The Business Layer is constituted by two reusable components that automate or support business processes that perform users and a set of web services and business objects using the Spring Framework applications. In the business layer invoke the web service for the real estate search, which has a search interface for both: agent and customer through a geolocation system for maps.

The Data Access Layer using JPA (Java Persistence API) and DAO (Data Access Objects), shared between Web components and invocations continued application by a MySQL database using JPA to access it .
The system has a search component, with the ability to generate and display accurate results and contextualized information contained on the site.

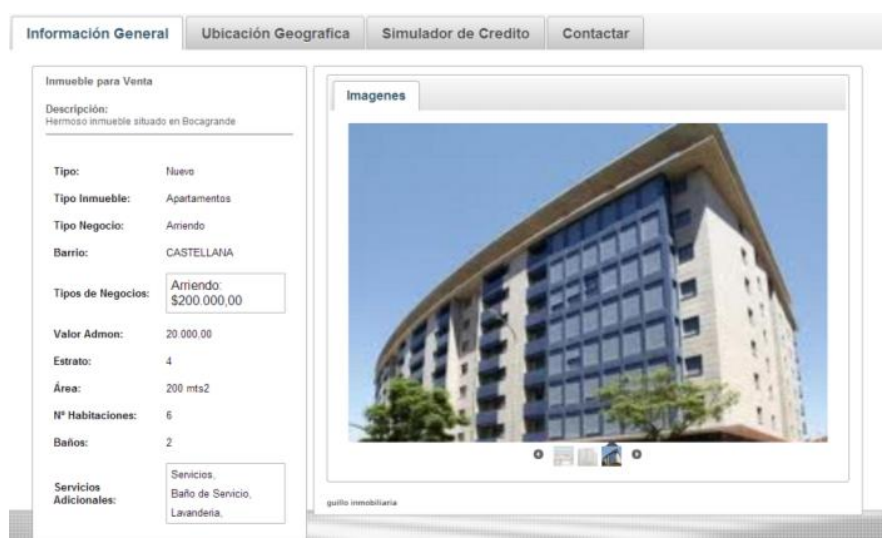

Figure 2. Real State Search

The search component connects to the API of Google through a Web Service consuming application resources and showing details of the property, mainly information from the environment in which it is located, information about what is around, views of the street, traffic volume, shops around, housing seen from the street, sidewalks, view entry the street and many other features.

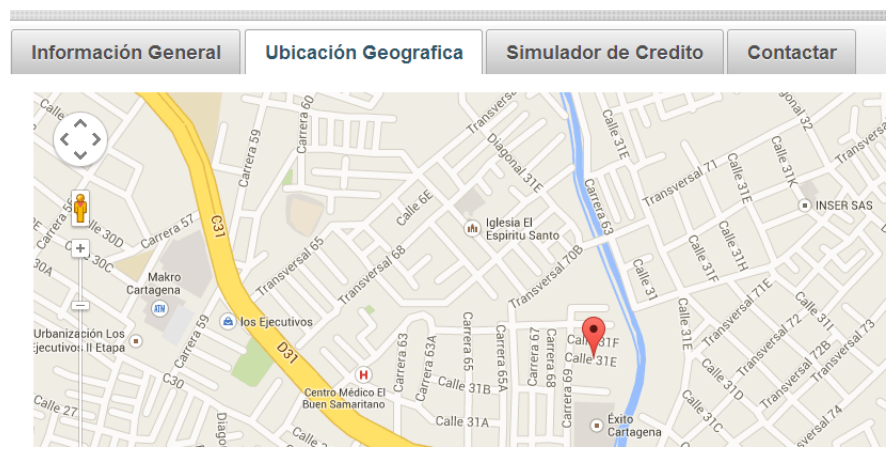

Figure 3. Geographical location through the API of Google Maps

\section{RESULTS AND CONCLUSIONS}

The technological platform was developed for the Real Estate Association of Cartagena, Colombia, an organization that brings together more than 17 real estate companies.

To validate the proposed architecture, we proceeded to the implementation of a software (tools and technologies described in III "Architecture Overview"). 
JUnit is the testing framework code that we used to performed the execution of Java classes to check the operation of the methods of the classes. Test cases were defined primarily for property search and the results compared. After field tests, it is observed that met the specifications, so the method returns JUnit class indicating that the procedure was successful. In turn, integration testing of the various components were made. This test was fundamental for a successful deployment of the application.

J2EE can be the best choice when choosing a technology on which to build enterprise applications because it has a high degree of structure and offer robust, scalable, flexible and portable applications. With this set of technologies real estate portal system with a component of property search, with the ability to generate and display built accurate results and contextualized information contained on the site.

INMO allows positioning of properties based scoring algorithms with Google Street View. Because there are different real estate in the application in a single schema, the app always respected the integrity of each one.

For its part, the administrative portal was implemented using Java platform, which integrates tools such as Street View and Google Maps to have a 3D view of the area, as well as include support services for customers and receive customized to user preferences alerts.

\section{REFERENCES}

[1] Correa, J.D.Y. \& Ricaurte, J.B.C., (2014). Web Application Deveploment Technologies Using Google Web Toolkit and Google App Engine-Java. IEEE Latin America Transactions, Vol. 12, No. 2, p.p. 372377.

[2] Guo, J., Xu, L., Gong, Z., Che, Ch-P., and Chaudhry, S.S., (2012). Semantic Inference on Heterogeneous E-Marketplace Activities, IEEE Transactions on Systems, Man, and Cybernetics, Vol. 42, No. 2, p.p. 316-330.

[3] Song Lin., \& Zhiguo Gao, \& Ke Xu, (2009). Web 2.0 Traffic Measurement: Analysis on Online Map Applications. ACM (978-160558-433-1/09/06), 7-12.

[4] Liu X., \& Hui Y., \& Sun W., \& Liang H. (2007). Towards Service Composition Based on Mashup. IEEE (978-0-7695-2926-4), 332 - 339

[5] Resch, B., and Zimmer, B., (2013).User Experience Design in Professional Map-Based Geo-Portals. ISPRS International Journal of Geo-Information. Vol. 2, No. 4., p.p. 1015-1037.

[6] Urbanavičiene, V., Kaklauskas, A., Zavadskas, E. K., \& Seniut, M., (2009). The web-based real estate multiple criteria negotiation decision support system: A new generation of decision support systems. International Journal of Strategic Property Management. Vol. 13, No. 3, p.p. $267-286$.

[7] Google (2013). Documentación para desarrolladores de Google Maps. Recuperado https://developers.google.com/maps/documentation/?hl=es [January 31, 2013]

[8] J. Guo, L. Xu, Z. Gong, Ch-P. Che and S. Chaudhry, "Semantic Inference on Heterogeneous E-Marketplace Activities". IEEE Trans. on Systems, Man, and Cybernetics. vol. 42, no. 2, pp. 316-330. 2012.
[9] S.Hariharaputhiran, "Challenges and Opportunities of E-Commerce", International Journal of Marketing, Financial Services \& Management Research, vol. 1, no. 3, pp. 98-108, 2012.

[10] V. Urbanavičienè. A. Kaklauskas, E. K. Zavadskas, and M. Seniut, "The Web-Based Real Estate Multiple Criteria Negotiation Decision Support System: A New Generation of Decision Support Systems", International Journal of Strategic Property Management, vol. 13, pp. 267-286. 2009.

[11] B. Resch and B. Zimmer, "User Experience Design in Professional Map-Based Geo-Portals", International Journal of Geo-Information, vol. 2, pp. 1015-1037. 2013

[12] E. Beracha and M. B. Wintoki, "Forecasting Residential Real Estate Price Changes from Online Search Activity", Journal of Real Estate Research, vol. 35, issue 3, pp. 283-312, 2013.

[13] L. Wu and E. Brynjolfsson, "The Future of Prediction: How Google Searches Foreshadow Housing Prices and Sales", NBER Chapters, in: Economics of Digitization National Bureau of Economic Research, Inc.. 2013.

[14] Y. Albanki, "A Web-Based Application for the Redlands Fire Department”, Master Thesis. University of Redlands, USA, 2012.

[15] H. Li-Xia, Z. Feng-Qing, J. Shu-Hong and M. Chao-Hua, "Design and Analysis of the Third-party Logisitics Management System Based on J2EE”, Advanced Engineering Forum, vol. 6, pp. 491-495. 2012.

[16] O. Morariu, C. Morariu and T. Borangiu, "Transparent Real Time Monitoring for Multi-tenant J2EE Applications", Journal of Control Engineering and Applied Informatics, vol.15, no.4 pp. 37-46, 2013.

[17] D. Krafzig, K. Banke, D. Slama, "Enterprise SOA Service-Oriented Architecture Best Practices". Prentice Hall. April 2005.

[18] Sing, I, Stearns, B, Jonson, M: Design Enterprise Applications with J2EE Plantaform, Second Edition. Ed: Addison-Wesley, 2002. ISBN 0201-78790-3

[19] M.Shaw, D. Garlan. Software Arquitecture: perspective on an emerging discipline. Prntice Hall, 1996.

[20] K-B. Yue, Z. Damania, R. Nilekani and K. Abeysekera, "The use of free and open source software in real-world capstone projects", Journal of Computing Sciences in Colleges, vol. 6, no. 4, pp. 85-92, 2011.

[21] K-B. Yue, "Experience on Mashup Development with End User Programming Environment", Journal of Information Systems Education, vol. 21, no. 1, pp. 111-119.2010.

[22] Z. Yu-lin and F. Zhong-liang, "Release of spatial information based on Google Maps API", Journal of Computer Applications, vol. 5, pp. 14501452, 2011.

[23] M. A. Butt and S. Li, "Open source based online map sharing to support real-time collaboration”, OSGeo Journal, vol. 10, pp. 4-15. 2011. 